\title{
Regulation of the sympathetic nervous system by nitric oxide and oxidative stress in the rostral ventrolateral medulla: 2012 Academic Conference Award from the Japanese Society of Hypertension
}

\author{
Takuya Kishi
}

Sympathoexcitation has an important role in the pathogenesis of hypertension. Previous studies have demonstrated that nitric oxide (NO) and/or oxidative stress in the brain are important for the regulation of the sympathetic nervous system. We have investigated the role of NO derived from an overexpression of endothelial NO synthase (eNOS) or oxidative stress in the rostral ventrolateral medulla (RVLM), which is known as a vasomotor center in the brainstem, on the regulation of the sympathetic nervous system. Our results indicated that NO derived from an overexpression of eNOS in the RVLM caused sympathoinhibition via an increase in $\gamma$-amino butyric acid and that angiotensin II type 1 receptor $\left(A T_{1} R\right)$-induced oxidative stress in the RVLM caused sympathoexcitation. We also demonstrated that oxidative stress in the RVLM caused sympathoexcitation via interactions with NO, effects on the signal transduction or apoptosis of the astrocytes. Furthermore, several orally administered $A T_{1} R$ blockers have been found to cause sympathoinhibition via a reduction in oxidative stress through the blockade of $A T_{1} R$ in the RVLM of hypertensive rats. In conclusion, our studies suggest that the increase in $A T_{1} R$-induced oxidative stress and/or the decrease in NO in the RVLM mainly cause sympathoexcitation in hypertension.

Hypertension Research (2013) 36, 845-851; doi:10.1038/hr.2013.73; published online 18 July 2013

Keywords: brain; nitric oxide; oxidative stress; sympathetic nerve activity

\section{INTRODUCTION}

Sympathoexcitation is closely associated with the pathogenesis of hypertension and the related organ damage. ${ }^{1-5}$ The sympathetic nervous system is regulated by the brain, especially the rostral ventrolateral medulla (RVLM) in the brainstem. ${ }^{6-7}$ There are inputs into the RVLM from baroreceptors, chemoreceptors and visceral receptors via the nucleus of the solitary tract $(\mathrm{NTS})^{7-12}$ and the paraventricular nucleus of the hypothalamus. ${ }^{8,13,14}$ Therefore, the RVLM is known as a vasomotor center, which determines the basal central sympathetic outflow.

The effect of nitric oxide (NO) and/or oxidative stress in the brain on the regulation of the sympathetic nervous system has been investigated in many previous studies. ${ }^{15-24}$ In particular, we have investigated the role of $\mathrm{NO}$ and/or oxidative stress in the RVLM. In the present review of our previous studies, we describe the importance of $\mathrm{NO}$ and/or angiotensin II type 1 receptor $\left(\mathrm{AT}_{1} \mathrm{R}\right)$ induced oxidative stress in the RVLM on the regulation of the sympathetic nervous system and the contribution of these mechanisms to the pathophysiology of hypertension.

\section{NO DERIVED FROM AN OVEREXPRESSION OF ENOS IN THE RVLM CAUSES SYMPATHOINHIBITION}

$\mathrm{NO}$ is an important mediator of intracellular signaling in various tissues, including the central nervous system..$^{25-27}$ There are three NO synthase (NOS) isoforms: the constitutive neuronal NOS (nNOS), endothelial NOS (eNOS) and inducible NOS (iNOS). A number of studies have demonstrated the localization of nNOS, eNOS and iNOS within the brain. ${ }^{28}$ Considerable evidence indicates that NOS acts on the cardiovascular system, including the receptors and effectors of the baroreflex pathway. ${ }^{15-17}$ We previously developed an in vivo technique for eNOS gene transfer into the NTS of rats to determine the effects of NO in the NTS on the sympathetic nervous system in a conscious state. $^{20,24,29-31}$ Compared to studies of the NTS, studies of the RVLM in both acute and anesthetized models have resulted in both sympathoexcitation and sympathoinhibition..$^{24,32-37}$

In an experiment using whole-cell patch-clamp recordings of visualized RVLM neurons from a brainstem slice, NO increased the amplitude of excitatory postsynaptic currents. ${ }^{37}$ Therefore, to 
investigate the role of $\mathrm{NO}$ in the RVLM in a conscious state, we applied the technique described above to study the RVLM. ${ }^{38-40}$ In those studies, prolonged sympathoinhibition was observed after the overexpression of eNOS in the RVLM ${ }^{38-40}$ Microinjection of either a NOS inhibitor or bicuculline, a $\gamma$-amino butyric acid (GABA) receptor antagonist, into the RVLM increased blood pressure to greater levels in the group with overexpression of eNOS in the RVLM compared with the control group. In addition, GABA levels in the RVLM measured by in vivo microdialysis increased in the group with overexpression of eNOS in the RVLM.

These results indicate that NO derived from the overexpression of eNOS in the RVLM caused sympathoinhibition mediated by an increased release of GABA. Similar to previous studies, ${ }^{16,41}$ we suggest that NO derived from the overexpression of eNOS would mainly mediate GABA release by the activation of $N$-methyl-D-aspartate (NMDA) receptors in presympathetic neurons in the RVLM. In addition, these studies provided convincing evidence that chronic changes in neurotransmitters/neuromodulators in the RVLM have a sustained impact on blood pressure in awake animals. In stroke-prone spontaneously hypertensive rats (SHRSP), overexpression of eNOS in the RVLM elicited greater depressor and sympathoinhibitory responses with the enhancement of GABA release than in normotensive rats. ${ }^{39}$ These results could indicate that NO dysfunction and the resulting disinhibition of the RVLM contribute to sympathoexcitation in SHRSP animals. Furthermore, overexpression of eNOS in the RVLM improved the impaired baroreflex control of heart rate in SHRSP animals. ${ }^{40}$ In summary, $\mathrm{NO}$ derived from an overexpression of eNOS in the RVLM caused sympathoinhibition via GABA release and facilitated the baroreflex function.

However, we were unable to fully determine whether NO in the RVLM causes sympathoinhibition because we examined the role of NO derived from an overexpression of eNOS in the RVLM. eNOS, nNOS and iNOS are all located in the RVLM. ${ }^{42}$ Previous studies have demonstrated that the application of a selective nNOS inhibitor into the RVLM caused a depressor effect. ${ }^{43-45}$ Moreover, the sympathoexcitation elicited by epicardial application of bradykinin was significantly attenuated by the unilateral microinjection of nonselective NOS inhibitors or a specific nNOS inhibitor into the RVLM, although the sympathoexcitation was unchanged by the injection of an eNOS inhibitor into the RVLM. ${ }^{46}$ Another previous report indicated that $\mathrm{NO}$ derived from $\mathrm{nNOS}$ induced sympathoexcitation via both NMDA and non-NMDA receptors. ${ }^{47}$ In contrast, overexpression of nNOS in the RVLM normalized the impaired baroreflex function due to sympathoinhibition in rats with heart failure. ${ }^{48}$

With regard to iNOS, we demonstrated that the overexpression of iNOS in the RVLM caused sympathoexcitation in a conscious state of normotensive rats ${ }^{49}$ and that the iNOS expression in the RVLM was enhanced in spontaneously hypertensive rats (SHR). ${ }^{50}$ However, other studies have indicated that the NO derived from iNOS caused sympathoinhibition ${ }^{4,45}$ via GABA receptors ${ }^{47}$ and that iNOS in the RVLM was reduced in SHR. ${ }^{42}$ Inconsistent results have also been shown within the same species, ${ }^{34-36}$ although the variable actions of NO in the RVLM observed in different species might be explained by interspecies variation in NOS density and distribution. ${ }^{32,33}$ These conflicting results suggest that the effects of $\mathrm{NO}$ on the regulation of the sympathetic nervous system would be different among NOS isoforms.

In addition, we have not clarified the effect of $\mathrm{NO}$ on the release of the excitatory amino acid glutamate in the RVLM. ${ }^{51}$ Stimulation of the cardiac sympathetic pathways activates RVLM neurons associated with glutamate as well as nNOS, ${ }^{52}$ and $\mathrm{NO}$ facilitates the action of glutamate in the RVLM through cyclic GMP/protein. ${ }^{37,47}$ Although we previously demonstrated that overexpression of eNOS in the RVLM increased the release of glutamate, microinjection of a glutamate receptor antagonist into the RVLM did not alter blood pressure. ${ }^{32}$ Further examinations to clarify the precise mechanisms for the effects of each NOS isoform and glutamate in the RVLM are necessary.

\section{OXIDATIVE STRESS IN THE RVLM CAUSES SYMPATHOEXCITATION IN HYPERTENSIVE RATS}

We focused on oxidative stress in the RVLM as a major sympathoexcitation factor because oxidative stress acts as a counterpart to NO. We measured oxidative stress in the RVLM using the electron-spin resonance method or the thiobarbituric acid-reactive substances method and demonstrated that oxidative stress was increased in the RVLM of SHRSP animals ${ }^{53-61}$ and SHR. ${ }^{62,63}$ We also confirmed that a microinjection of tempol, a membrane-permeable superoxide dismutase (SOD) mimetic, into the RVLM decreased blood pressure and heart rate in SHRSP animals but not in normotensive rats. Furthermore, we transfected adenoviral vectors encoding the manganese SOD (MnSOD) gene into the RVLM in SHRSP animals. Overexpression of MnSOD in the RVLM decreased blood pressure, heart rate and urinary norepinephrine excretion in SHRSP animals but not in normotensive rats. We also found reduced SOD activity in the RVLM of SHRSP animals compared with normotensive rats, and this reduction led to a decreased capability for scavenging superoxide anions.

These findings indicate that oxidative stress in the RVLM causes sympathoexcitation, and this mechanism was involved in the neural pathophysiology of hypertension in SHRSP animals. We have also demonstrated that oxidative stress in the RVLM caused sympathoexcitation in several other hypertensive models, such as salt-induced hypertension, ${ }^{62}$ dietary-induced hypertension ${ }^{57,64}$ and experimental jet lag. ${ }^{56}$ Moreover, these results are consistent with previous studies of other investigators. ${ }^{65,66}$ In addition, Oliveira-Sales et al. ${ }^{67-69}$ suggested that sympathoexcitation in renovascular (two-kidney oneclip) hypertensive rats was associated with oxidative stress in the RVLM and paraventricular nucleus of the hypothalamus. These results strongly suggest that the increase in oxidative stress in the RVLM is an important cause, not a result, of the sympathoexcitation, which then leads to hypertension.

\section{SOURCES OF OXIDATIVE STRESS IN THE RVLM}

Among the sources of oxidative stress in the RVLM, such as nicotinamide adenine dinucleotide phosphate $[\mathrm{NAD}(\mathrm{P}) \mathrm{H}]$ oxidase, xanthine oxidase, uncoupled NOS and mitochondria, we demonstrated that mainly the activation of the $\mathrm{AT}_{1}$ receptor/ $\mathrm{NAD}(\mathrm{P}) \mathrm{H}$ oxidase produced the oxidative stress in the RVLM of SHRSP animals. ${ }^{58,70,71}$ These results are consistent with a previous report. ${ }^{72}$ The renin angiotensin system in the brain is associated with enhanced central sympathetic outflow, ${ }^{73-78}$ and mitochondria-derived oxidative stress has been shown to mediate sympathoexcitation induced by angiotensin II in the brain. ${ }^{79,80}$ Angiotensin II exogenously administered into the RVLM elicited a pressor response via sympathoexcitation. ${ }^{81,82}$ Moreover, the inhibition of the $\mathrm{AT}_{1}$ receptor in the RVLM by $\mathrm{AT}_{1}$ receptor blockers caused sympathoinhibition in hypertensive rats. ${ }^{57-59,62,64,71,81}$ We found that the overexpression of $\mathrm{MnSOD}$ attenuated the angiotensin II-induced pressor response associated with oxidative stress in the $\mathrm{RVLM}^{70}$ All of these results indicate that the $\mathrm{AT}_{1}$ receptor $/ \mathrm{NAD}(\mathrm{P}) \mathrm{H}$ oxidase may be the main 
source of oxidative stress in the RVLM of hypertensive rats. Moreover, we showed that Racl was associated with the activation of $\mathrm{NAD}(\mathrm{P}) \mathrm{H}$ oxidase. $^{20,22-24,55,79}$

$\mathrm{Rac1}$ is a small $\mathrm{G}$ protein involved in integrating the intracellular transduction pathways toward $\mathrm{NAD}(\mathrm{P}) \mathrm{H}$ activation and requires lipid modifications to migrate from the cytosol to the cell membrane. The inhibition of Racl caused by the transfection of the adenovirus vectors encoding a dominant-negative Rac1 into the RVLM or NTS decreased blood pressure, heart rate and urinary norepinephrine excretion in SHRSP animals but not in normotensive rats. ${ }^{22,79} \mathrm{~A}$ blockade of Racl translocation from the cytosol to the membrane in the RVLM of SHRSP animals caused sympathoinhibition via a decrease in $\mathrm{NAD}(\mathrm{P}) \mathrm{H}$ oxidase activity and oxidative stress. ${ }^{55}$ Thus, our findings indicate that activation of the $\mathrm{AT}_{1}$ receptor/NAD $(\mathrm{P}) \mathrm{H}$ oxidase associated with Rac1 mainly produced oxidative stress in the RVLM of SHRSP animals.

\section{MECHANISMS OF OXIDATIVE STRESS-INDUCED SYMPATHOEXCITATION IN THE RVLM}

We have demonstrated several mechanisms by which oxidative stress in the RVLM causes sympathoexcitation. Superoxide interacts with NO. As we consider that NO in the RVLM causes sympathoinhibition, ${ }^{29,38,39}$ decreased NO bioavailability in the RVLM induced by superoxide might cause sympathoexcitation. Recently, we demonstrated that a reduction in NO-mediated GABA release in the RVLM was involved in superoxide-induced sympathoexcitation in SHRSP animals. ${ }^{83}$ Regarding the relationship between superoxide and NO, we should also focus on the formation of peroxynitrite because the kinetics of the formation of peroxynitrite from superoxide and $\mathrm{NO}$ are strong. ${ }^{84}$ In fact, peroxynitrite in the RVLM has an excitotoxic effect. ${ }^{85}$

A recent study suggested that reactive oxygen species and reactive nitrogen species, such as peroxynitrite, could dose dependently regulate iNOS function and that peroxynitrite reduces both $\mathrm{NO}$ and superoxide productions via enzymatic iNOS dysfunction. ${ }^{86}$ Another report indicated that an interaction between $\mathrm{NO}$ and superoxide in the RVLM via the formation of peroxynitrite contributed to the hypotensive effect of NO after overexpression of eNOS in SHR. ${ }^{87}$ The role of peroxynitrite in the RVLM on the regulation of the sympathetic nervous system should be further examined.

The excitatory amino acid glutamate in the RVLM is known to cause strong sympathoexcitation. ${ }^{6,7}$ We recently demonstrated that oxidative stress modulates the balance between glutamate and GABA in the RVLM of hypertensive rats. ${ }^{63}$ The results are consistent with previous reports, which demonstrated that $\mathrm{NAD}(\mathrm{P}) \mathrm{H}$ oxidase-derived superoxide in the RVLM was involved in the angiotensin II-induced pressor response via an enhancement of the presynaptic release of glutamate. ${ }^{72}$ We hypothesize that glutamate in the RVLM might be involved in oxidative stress-evoked sympathoexcitation.

We have also focused on the signal transduction associated with oxidative stress. The $\mathrm{AT}_{1}$ receptor activates caspase- 3 in the RVLM through the Ras/mitogen-activated protein kinase/extracellular signal-regulated kinase, which is involved in sympathoexcitation in SHRSP animals. ${ }^{71}$ The activities of Ras, p38 mitogen-activated protein kinase, extracellular signal-regulated kinase and caspase- 3 in the RVLM were elevated in SHRSP animals compared with those in normotensive rats. The phosphorylation of the pro-apoptotic proteins Bax and Bad, which release cytochrome $c$ in the mitochondria, was shown to activate caspase- $3 .^{71}$ In contrast, the phosphorylation of the anti-apoptotic protein Bcl-2 inhibited caspase- 3 activation. Intracerebroventricular infusion of a caspase-3 inhibitor reduced blood pressure and heart rate with sympathoinhibition in SHRSP animals but not in normotensive rats. Intracerebroventricular infusion of an $\mathrm{AT}_{1}$ receptor blocker caused sympathoinhibition and also reduced the activities of Ras, p38 mitogen-activated protein kinase, extracellular signal-regulated kinase and caspase-3 in the RVLM of SHRSP animals. These results are consistent with a previous report, which indicated that $\mathrm{NAD}(\mathrm{P}) \mathrm{H}$ oxidase derived superoxide and functioned in the activation of p38 mitogen-activated protein kinase or extracellular signal-regulated kinase1/2 by angiotensin II in the RVLM. ${ }^{72}$ Although the relationship between oxidative stress and activation of these kinases is bidirectional, ${ }^{88}$ these pathways could exist downstream of the $\mathrm{AT}_{1}$ receptor in the RVLM of SHRSP animals and could be related to the blood pressure elevation and sympathoexcitation observed in SHRSP animals.

Recently, additional central mechanisms of sympathoexcitation associated with oxidative stress were considered, such as perivascular macrophages in the brain, ${ }^{89,90}$ transcription factor nuclear factor kappa- $\mathrm{B}^{91}$ and microglial cytokines ${ }^{92}$ in the brain. We also recently demonstrated that neuron-astrocyte uncoupling mediated by $\mathrm{AT}_{1}$ receptor-induced oxidative stress in the RVLM caused sympathoexcitation in SHRSP animals. ${ }^{93,94}$

There are several unsolved issues. First, there may be multiple targets of oxidative stress in the RVLM. We have not clarified which types of cells, such as presympathetic neurons, interneurons or the axon terminals from NTS and paraventricular nucleus to the RVLM, are targets of oxidative stress in the RVLM. We demonstrated that oxidative stress triggered calcium influx in the neural cells; this mitochondrial calcium accumulation led to sympathoexcitation associated with mitochondrial oxidative stress production. ${ }^{70}$ These results were similar to a previous report. ${ }^{80}$ We also determined that oxidative stress in the RVLM enhanced glutamatergic excitatory inputs and attenuated GABAergic inhibitory inputs from the paraventricular nucleus into the RVLM. ${ }^{63}$ Interestingly, Chan et al. ${ }^{72}$ clearly demonstrated that $\mathrm{NAD}(\mathrm{P}) \mathrm{H}$ oxidase-derived superoxide in the RVLM was involved in the angiotensin II-induced pressor response via enhancement of the presynaptic release of glutamate to RVLM neurons. Our recent results indicate that oxidative stressinduced sympathoexcitation might be mediated by the apoptosis of astrocytes in the RVLM. ${ }^{71,93}$ However, we have not conducted electrophysiological examinations to clarify the effect of oxidative stress on the electrophysiological characteristics of the RVLM neurons.

Several previous studies performed by Kumagai et al. ${ }^{95-97}$ indicated that the RVLM bulbospinal neurons in SHR depolarized and the firing rate increased by angiotensin II. Furthermore, angiotensin II produced a sustained inward current and increased the frequency and amplitude of the excitatory postsynaptic currents. These angiotensin II-evoked responses in the RVLM might be associated with oxidative stress, and angiotensin II-induced oxidative stress has the potential to reduce the expression of the voltage-gated potassium channel in the RVLM. ${ }^{98,99}$ Moreover, the $\mathrm{AT}_{1}$ receptor enhanced the frequency of glutamatesensitive spontaneous excitatory postsynaptic currents in the RVLM. ${ }^{72}$ Further studies to explore these unsolved questions are required.

\section{EFFECTS OF AT ${ }_{1}$ RECEPTOR BLOCKERS ON OXIDATIVE STRESS IN THE RVLM AND SYMPATHETIC NERVOUS SYSTEM} The $\mathrm{AT}_{1}$ receptor in the brain has an important role in the pathophysiology of hypertension. $7,9,73,74,79,100,101$ Interestingly, peripherally administered $\mathrm{AT}_{1}$ receptor blockers can penetrate the blood-brain barrier and block the $\mathrm{AT}_{1}$ receptor within and outside the brain, although the extent of the blocking action within the brain varies among $\mathrm{AT}_{1}$ receptor blockers. ${ }^{58,64,102-105} \mathrm{~A}$ high density of $\mathrm{AT}_{1}$ 
receptor is present in brain regions that are involved in the regulation of the sympathetic nervous system, such as the circumventricular organs outside of the blood-brain barrier that peripherally administered $\mathrm{AT}_{1}$ receptor blockers are able to access, and also regions inside the blood-brain barrier. ${ }^{101}$

Recent studies suggest that systemically administered $\mathrm{AT}_{1}$ receptor blockers also act on the $\mathrm{AT}_{1}$ receptor within the brain, thereby reducing blood pressure in hypertensive rats. ${ }^{22,58,64,103,106-108}$ The extent of the actions of $\mathrm{AT}_{1}$ receptor blockers within the brain might depend partly on the lipophilicity and pharmacokinetics of the blockers. ${ }^{102,105}$ We have also examined the sympathoinhibitory effect via a reduction in oxidative stress through the inhibition of the $\mathrm{AT}_{1}$ receptor in the brain, and our results are consistent with many previous studies. ${ }^{64,101-107}$ Orally administered telmisartan or olmesartan reduced blood pressure and urinary norepinephrine excretion in SHRSP animals and was associated with a reduction in oxidative stress production in the brainstem, including the RVLM. ${ }^{22,108}$ Orally administered telmisartan has been shown to inhibit $\mathrm{AT}_{1}$ receptor-induced oxidative stress in the RVLM and cause sympathoinhibition in SHRSP animals to a greater extent than candesartan, in spite of similar depressor effects. ${ }^{58}$ Similar results were obtained in obesity-induced hypertensive rats treated with telmisartan or losartan. ${ }^{64}$ Thus, it is conceivable that orally administered $\mathrm{AT}_{1}$ receptor blockers could cause sympathoinhibition associated with the blockade of the $\mathrm{AT}_{1}$ receptor in the RVLM. Moreover, the sympathoinhibitory effects caused by orally administered $\mathrm{AT}_{1}$ receptor blockers may not be class effects.

\section{SYMPATHOINHIBITION BY TARGETING OXIDATIVE STRESS IN THE RVLM OF HYPERTENSIVE ANIMALS}

3-Hydroxy-3-methylglutaryl coenzyme A reductase inhibitors (statins) are potent inhibitors of cholesterol biosynthesis. In addition, a previous study suggested that statins reduce blood pressure in patients with hypertension, ${ }^{109}$ and the potential sympathoinhibition of statins has been demonstrated. ${ }^{110-112}$ We have also demonstrated that orally administered atorvastatin causes sympathoinhibition and improves impaired baroreflex sensitivity via a reduction in oxidative stress through the inhibition of the $\mathrm{AT}_{1}$ receptor- $\mathrm{NAD}(\mathrm{P}) \mathrm{H}$ oxidase and the upregulation of MnSOD in the RVLM of SHRSP animals; ${ }^{54,55,111}$ these findings are consistent with a previous study of the vasculature. $^{113}$ Moreover, we also determined that orally administered atorvastatin could increase NOS in the brainstem of SHRSP animals. ${ }^{114}$ From these results, we consider that statins have a potential to cause sympathoinhibition via a reduction in oxidative stress and/or an activation of NOS in the RVLM.

Several calcium channel blockers have been confirmed to cause sympathoinhibition via a reduction in oxidative stress in the RVLM of hypertensive rats. Orally administered amlodipine ${ }^{115}$ or azelnidipine $e^{61}$ caused sympathoinhibition via a reduction in oxidative stress in the RVLM of SHRSP animals. We confirmed that orally administered azelnidipine inhibited the $\mathrm{NAD}(\mathrm{P}) \mathrm{H}$ oxidase activity and activated MnSOD in the RVLM of SHRSP animals. ${ }^{61}$ Furthermore, a combination of atorvastatin and amlodipine ${ }^{60}$ or olmesartan and azelnidipine $^{116}$ had additive effects of sympathoinhibition via a reduction in oxidative stress in the RVLM.

Interestingly, caloric restriction ${ }^{57}$ and exercise training ${ }^{59}$ have been shown to have a pivotal role in sympathoinhibition via a reduction in oxidative stress through the blockade of the $\mathrm{AT}_{1}$ receptor in hypertensive rats. These results suggest that adipocytokines and/or insulin resistance may affect the $\mathrm{AT}_{1}$ receptor in the RVLM and cause sympathoexcitation.

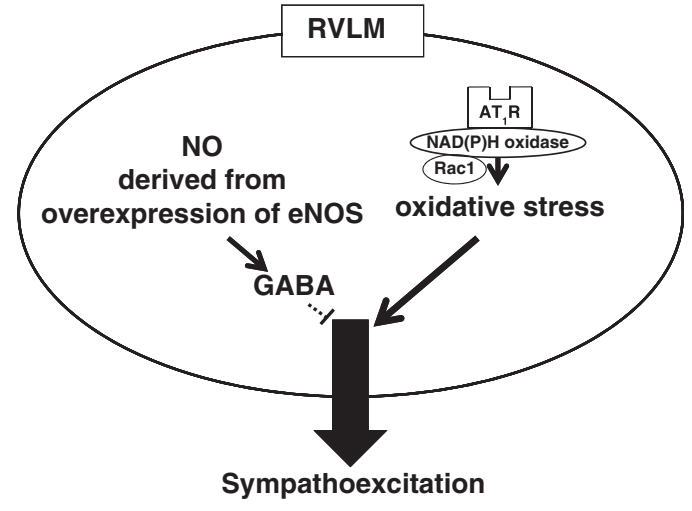

Figure 1 A schema showing our concept of the regulation of sympathetic nerve activity via NO derived from the overexpression of eNOS and $A T_{1} R$ induced oxidative stress in the RVLM. GABA, $\gamma$-amino butyric acid; $\mathrm{NAD}(\mathrm{P}) \mathrm{H}$ oxidase, nicotinamide adenine dinucleotide phosphate.

\section{PERSPECTIVES AND CONCLUSIONS}

The figure 1 shows our conceptualization of the regulation of the sympathetic nervous system via NO derived from overexpression of eNOS and/or $\mathrm{AT}_{1}$ receptor-induced oxidative stress in the RVLM. Regarding treatment for subnormal sympathoexcitation in cardiovascular diseases, our studies and other reports indicate that a blockade of the $\mathrm{AT}_{1}$ receptor in the RVLM may be necessary. ${ }^{64,101-108}$ $\mathrm{AT}_{1}$ receptor blockers are widely used in the treatments for hypertension. ${ }^{117}$ In addition, $\mathrm{AT}_{1}$ receptor blockers may have protective effects on neurons, thereby reducing the incidence of stroke and improving cognition. ${ }^{117,118}$

Recent results from studies of renal nerve ablation in patients with resistant hypertension suggest that renal afferent nerves may also contribute to blood pressure elevation. ${ }^{119-121}$ Renal afferent nerves project directly into many areas in the central nervous system, such as the NTS and hypothalamus. ${ }^{122,123}$ Oxidative stress was shown to mediate sympathoexcitation in the phenol renal injury model of hypertension in which the renal afferent nerves are stimulated. ${ }^{124} \mathrm{In}$ this model, the $\mathrm{AT}_{1}$ receptor and $\mathrm{NAD}(\mathrm{P}) \mathrm{H}$ oxidase in the brain are activated. Previous studies have suggested that increased oxidative stress production and reduced nNOS expression may be involved in these mechanisms, and these changes lead to the alteration of cytokines in the brain. ${ }^{124,125}$

We suggest that the $\mathrm{AT}_{1}$ receptor and related oxidative stress production in the RVLM should be therapeutic targets for the treatment of abnormal sympathoexcitation in hypertension. In conclusion, our studies suggest that the increase in $\mathrm{AT}_{1}$ receptorinduced oxidative stress and/or decrease in NO in the RVLM mainly cause sympathoexcitation in hypertension.

\section{CONFLICT OF INTEREST}

The author declares no conflict of interest.

\section{ACKNOWLEDGEMENTS}

This study was supported by a Grant-in-Aid for Scientific Research from the Japan Society for the Promotion of Science (15590757, 17590745, 19390231 and 22790709) and partially by a Kimura Memorial Foundation Research Grant. I would like to express great appreciation to Professors Yoshitaka Hirooka, Kenji Sunagawa and Akira Takeshita. Furthermore, I express special thanks to Satomi and Jiro Konno. 
1 Grassi G. Assessment of sympathetic cardiovascular drive in human hypertension: achievements and perspectives. Hypertension 2009; 54: 690-697.

2 Grassi G. Sympathetic neural activity in human hypertension and related diseases. Am J Hypertens 2010; 23: 1052-1060.

3 Grassi G, Seravalle G, Quarti-Trevano F. The 'neurogenic hypothesis' in hypertension: current evidence. Exp Physiol 2010; 95: 581-586.

4 Esler M. The 2009 Carl Ludwig lecture: pathophysiology of the human sympathetic nervous system in cardiovascular diseases: the transition from mechanisms to medical management. J Appl Physiol 2010; 108: 227-237.

5 Mauo K, Lambert GW, Esler MD, Rakugi H, Ogihara T, Schlaich MP. The role of sympathetic nervous system activity in renal injury and end-stage renal disease. Hypertens Res 2010; 33: 521-528.

6 Dampney RAL. Functional organization of central pathways regulating the cardiovascular system. Physiol Rev 1994; 74: 323-364.

7 Guyenet PG. The sympathetic control of blood pressure. Nat Rev Neurosci 2006; 7: 335-346.

8 Pilowsky PM, Goodchild AK. Baroreceptor reflex pathways and neurotransmitters: 10 years on. J Hypertens 2002; 20: 1675-1688.

9 Sved AF, Ito S, Sved JC. Brainstem mechanisms of hypertension: role of the rostral ventrolateral medulla. Curr Hypertens Rep 2003; 5: 262-268.

10 Dampney RAL, Polson JW, Potts PD, Hirooka Y, Horiuchi J. Functional organization of brain pathways subserving the baroreceptor reflex: studies in conscious animals using immediate early gene expression. Cell Mol Neurobiol 2003; 23 : 597-616.

11 Campos RR, Bergamschi CT. Neurotransmission alterations in central cardiovascular control in experimental hypertension. Curr Hypertens Rev 2006; 2: 193-198.

12 Carlson SH, Wyss JM. Neurohormonal regulation of the sympathetic nervous system: new insights into central mechanisms of action. Curr Hypertens Rep 2008; 10: 233-240.

13 Dampney RAL, Horiuchi J, Killinger S, Sheriff MJ, Tan PSP, McDowall LM. Long-term regulation of arterial blood pressure by hypothalamic nuclei: some critical questions. Clin Exp Pharmacol Physiol 2005; 32: 419-425.

14 Coote $\mathrm{JH}$. Landmarks in understanding the central nervous control of the cardiovascular system. Exp Physiol 2007; 92: 3-18.

15 Krukoff TL. Central action of nitric oxide in regulation of autonomic functions. Brain Res Rev 1999; 30: 52-65.

16 Patel K, Li YF, Hirooka Y. Role of nitric oxide in central sympathetic outflow. Exp Biol Med 2001; 226: 814-824.

17 Zanzinger J. Role of nitric oxide in the neural control of cardiovascular function. Cardiovasc Res 1999; 43: 639-649.

18 Tai MH, Wang LL, Wu KLH, Chan JYH. Increased superoxide anion in rostral ventrolateral medulla contributes to hypertension in spontaneously hypertensive rats via interactions with nitric oxide. Free Rad Biol Med 2005; 38: 450-462.

19 Peterson JR, Sharma RV, Davisson RL. Reactive oxygen species in the neuropathogenesis of hypertension. Curr Hypertens Rep 2006; 8: 232-241.

20 Hirooka Y. Role of reactive oxygen species in brainstem in neural mechanisms of hypertension. Auton Neurosci 2008; 142: 20-24.

21 Campos RR. Oxidative stress in the brain and arterial hypertension. Hypertens Res 2009; 32: 1047-1048.

22 Hirooka Y, Sagara Y, Kishi T, Sunagawa K. Oxidative stress and central cardiovascular regulation: pathogenesis of hypertension and therapeutic aspects. Circ J 2010; 274: 827-835.

23 Hirooka Y. Oxidative stress in the cardiovascular center has a pivotal role in the sympathetic activation in hypertension. Hypertens Res 2011; 34: 407-412.

24 Hirooka Y, Kishi T, Sakai K, Takeshita A, Sunagawa K. Imbalance of central nitric oxide and reactive oxygen species in the regulation of sympathetic activity and neural mechanisms of hypertension. Am J Physiol 2011; 300: R818-R826.

25 Garthwaite J. Concepts of neural nitric oxide-mediated transmission. Eur J Neurosci 2008; 27: 2783-2802.

26 Talman WT, Dragon DN. Transmission of arterial baroreflex signals depends on neuronal nitric oxide synthase. Hypertension 2004; 43: 820-824.

27 Talman WT. NO and central cardiovascular control: a simple molecule with a complex story. Hypertension 2006; 48: 552-554.

28 TFC Batten, Atkinson L, Deuchars J. Nitric oxide systems in the medulla oblongata and their involvement in autonomic control. Functional neuroanatomy of the nitric oxide system, in Handbook of Chemical Neuroanatomy (eds Steinbusch HWM, De Vente J and Vincent SR) (Elsevier, Amsterdam, The Netherlands, 2000) pp $177-213$.

29 Hirooka Y, Kishi T, Sakai K, Shimokawa H, Takeshita A. Effects of overproduction of nitric oxide in the brain stem on the cardiovascular response in conscious rats. J Cardiovasc Pharmacol 2003; 41 (Suppl 1), S119-S126.

30 Hirooka Y, Shigematsu H, Kishi T, Kimura Y, Ueta Y, Takeshita A. Reduced nitric oxide synthase in the brainstem contributes to enhanced sympathetic drive in rats with heart failure. J Cardiovasc Pharmacol 2003; 42 (Suppl 1), S111-S115.

31 Sakai K, Hirooka Y, Matsuo I, Eshima K, Shigematsu H, Shimokawa H, Takeshita A. Overexpression of eNOS in NTS causes hypotension and bradycardia in vivo. Hypertension 2000; 36: 1023-1028.

32 Hirooka Y, Polson JW, Dampney RAL. Pressor and sympathoexcitatory effects of nitric oxide in the rostral ventrolateral medulla. J Hypertens 1996; 14: 1317-1324.

33 Zanzinger J, Seller H. Species differences in the distribution of nitric oxide synthase in brain stem regions that regulate sympathetic activity. Brain Res 1997; 764 265-268.
34 Chen SY, Mao SP, Chai CY. Role of nitric oxide on pressor mechanisms within the dorsomedial and rostral ventrolateral medulla in anesthetized cats. Clin Exp Pharmacol Physiol 2001; 28: 155-163.

35 Morimoto S, Sasaki S, Miki S, Kawa T, Nakamura K, Itoh H, Nakata T, Takeda K, Nakagawa M, Fushiki S. Nitric oxide is an excitatory modulator in the rostral ventrolateral medulla in rats. Am J Hypertens 2000; 13: 1125-1134.

36 Tseng CJ, Liu HY, Lin HC, Ger LP, Tung CS, Yen MH. Cardiovascular effects of nitric oxide in the brain stem nuclei of rats. Hypertension 1996; 27: 36-42.

37 Huang CC, Chan SH, Hsu KS. cGMP/protein kinase G-dependent potentiation of glutamatergic transmission induced by nitric oxide in immature rat rostral ventrolateral medulla neurons in vitro. Mol Pharmacol 2003; 64: 521-532.

38 Kishi T, Hirooka Y, Sakai K, Shigematsu H, Shimokawa H, Takeshita A. Overexpression of eNOS in the RVLM causes hypotension and bradycardia via GABA release. Hypertension 2001; 38: 896-901.

39 Kishi T, Hirooka Y, Ito K, Sakai K, Shimokawa H, Takeshita A. Cardiovascular effects of overexpression of endothelial nitric oxide synthase in the rostral ventrolateral medulla in stroke-prone spontaneously hypertensive rats. Hypertension 2002; 39: 264-268.

40 Kishi T, HIrooka Y, Kimura Y, Sakai K, Ito K, Shimokawa H, Takeshita A. Overexpression of eNOS in RVLM improves impaired baroreflex control of heart rate in SHRSP. Hypertension 2003; 41: 255-260.

41 Smith JK, Barron KW. GABAergic responses in ventrolateral medulla in spontaneously hypertensive rats. Am J Physiol 1990; 258: R450-R456.

42 Chang AY, Chan JY, Chan SH. Differential distribution of nitric oxide synthase isoforms in the rostral ventrolateral medulla of the rat. J Biomed Sci 2003; 10: 285-291.

43 Guo ZL, Tjen-A-Looi SC, Fu LW, Longhurst JC. Nitric oxide in rostral ventrolateral medulla regulates cardiac-sympathetic reflexes: role of synthase isoforms. Am J Physiol 2009; 297: H1478-H1486.

44 Martins-Pinge MC, Garcia MR, Zoccal DB, Crestani CC, Pinge-Filho P. Differentia influences of iNOS and nNOS inhibitors on rostral ventrolateral medullary mediated cardiovascular control in conscious rats. Auton Neursci 2007; 131: 65-69.

45 Chan SH, Wang LL, Chan JY. Differential cardiovascular responses to blockade of nNOS or iNOS in rostral ventrolateral medulla of the rats. Br J Pharmacol 2001; 133: 606-614.

46 Ibrahim BM, Abdel-Rahman AA. Enhancement of rostral ventrolateral medulla neuronal nitric-oxide synthase-nitric-oxide signaling mediates the central cannabinoid receptor 1-evoked pressor response in conscious rats. J Pharmacol Exp Ther 2012 ; 341: 579-586.

47 Chan SH, Wang LL, Chan JY. Differential engagement of glutamate and GABA receptors in cardiovascular actions of endogenous nNOS or iNOS at rostral ventrolateral medulla of rats. Br J Pharmacol 2003; 138: 584-593.

48 Wang Y, Patel KP, Cornish KG, Channon KM, Zucker IH. nNOS gene transfer to RVLM improves baroreflex function in rats with chronic heart failure. Am J Physiol 2003; 285: H1660-H1667.

49 Kimura Y, Hirooka Y, Sagara Y, Ito K, Kishi T, Shimokawa H, Takeshita A, Sunagawa K. Overexpression of inducible nitric oxide synthase in rostral ventrolateral medulla causes hypertension and sympathoexcitation via an increase in oxidative stress. Circ Res 2005; 96: 252-260.

50 Kimura Y, Hirooka Y, Kishi T, Ito K, Sagara Y, Sunagawa K. Role of inducible nitric oxide synthase in rostral ventrolateral medulla in blood pressure regulation in spontaneously hypertensive rats. Clin Exp Hypertens 2009; 31: 281-286.

51 Chan JY, Wang LL, Wu KL, Chan SH. Reduced functional expression and molecular synthesis of inducible nitric oxide synthase in rostral ventrolateral medulla of spontaneously hypertensive rats. Circulation 2001; 104: 1676-1681.

52 Guo ZL, Longhurst J. Responses of neurons containing VGLUT3/nNOS-cGMP in the rVLM to cardiac stimulation. Neuroreport 2006; 17: 255-259.

53 Kishi T, Hirooka Y, Kimura Y, Ito K, Shimokawa H, Takeshita A. Increased reactive oxygen species in rostral ventrolateral medulla contributes to neural mechanisms of hypertension in stroke-prone spontaneously hypertensive rats. Circulation 2004; 109: 2357-2362.

54 Kishi T, Hirooka Y, Shimokawa H, Takeshita A, Sunagawa K. Atorvastatin reduced oxidative stress in the rostral ventrolateral medulla of stroke-prone spontaneously hypertensive rats. Clin Exp Hypertens 2008; 30: 3-11.

55 Kishi T, Hirooka Y, Konno S, Sunagawa K. Sympathoinhibition induced by centrally administered atorvastatin is associated with alteration of $\mathrm{NAD}(\mathrm{P}) \mathrm{H}$ oxidase and $\mathrm{Mn}$ superoxide dismutase activity in rostral ventrolateral medulla of stroke-prone spontaneously hypertensive rats. J Cardiovasc Pharmacol 2010b; 55: 184-190.

56 Kishi T, Sunagawa K. Experimental 'jet lag' causes sympathoexcitation via oxidative stress through AT1 receptor in the brainstem. Conf Proc IEEE Eng Med Biol Soc 2011; 2011: 1969-1972.

57 Kishi T, Hirooka Y, Ogawa K, Konno S, Sunagawa K. Calorie restriction inhibits sympathetic nerve activity via anti-oxidant effect in the rostral ventrolateral medulla of obesity-induced hypertensive rats. Clin Exp Hypertens 2011; 33: 240-245.

58 Kishi T, Hirooka Y, Sunagawa K. Sympathoinhibition caused by orally administered telmisartan through inhibition of AT(1) receptor in the rostral ventrolateral medulla. Hypertens Res 2012; 35: 940-946.

59 Kishi T, Hirooka Y, Katsuki M, Ogawa K, Shinohara K, Isegawa K, Sunagawa K. Exercise training causes sympathoinhibition through antioxidant effect in the rostral ventrolateral medulla of hypertensive rats. Clin Exp Hypertens 2012; 34: 278-283.

60 Kishi T, Sunagawa K. Combination therapy of atorvastatin and amlodipine inhibits sympathetic nervous system activation and improves cognitive function in hypertensive rats. Circ J 2012; 76: 1934-1941. 
61 Konno S, Hirooka Y, Araki S, Koga Y, Kishi T, Sunagawa K. Azelnidipine decreases sympathetic nerve activity via antioxidant effect in the rostral ventrolateral medulla of stroke-prone spontaneously hypertensive rats. J Cardiovasc Pharmacol 2008; 52: 555-560.

62 Koga Y, Hirooka Y, Araki S, Nozoe M, Kishi T, Sunagawa K. High salt intake enhances blood pressure increase during development of hypertension via oxidative stress in rostral ventrolateral medulla of spontaneously hypertensive rats. Hypertens Res 2008; 31: 2075-2083

63 Nishihara M, Hirooka Y, Matsukawa R, Kishi T, Sunagawa K. Oxidative stress in the rostral ventrolateral medulla modulates excitatory and inhibitory inputs in spontaneously hypertensive rats. J Hypertens 2012; 30: 97-106.

64 Konno S, Hirooka Y, Kishi T, Sunagawa K. Sympatho-inhibitory effect of telmisartan through the reduction of oxidative stress in rostral ventrolateral medulla of obesityinduced hypertensive rat. J Hypertens 2012; 30: 1992-1999.

65 Fujita M, Ando K, Nagae A, Fujita T. Sympathoexcitation by oxidative stress in the brain mediates arterial pressure elevation in salt-sensitive hypertension. Hypertension 2007: 50: 360-367.

66 Nagae A, Fujita M, Kawarazaki H, Matsui H, Ando K, Fujita T. Sympathoexcitation by oxidative stress in the brain mediates arterial pressure elevation in obesity-induced hypertension. Circulation 2009; 119: 978-986.

67 Oliveira-Sales EB, Dugaich AP, Carillo BA, Abreu NP, Boim MA, Martins PJ, D'Ameida $\mathrm{V}$, Dolnkoff MS, Bergamaschi CT, Campos RR. Oxidative stress contributes to renovascular hypertension. Am J Hypertens 2008; 21: 98-104.

68 Oliveira-Sales EB, Nishi EE, Carillo BA, Dolnikoff MS, Bergamaschi CT, Campos RR. Oxidative stress in the sympathetic premotor neurons contributes to sympathetic activation in renovascular hypertension. Am J Hypertens 2009; 22: 484-492.

69 Oliveira-Sales EB, Colombari DSA, Davisson RL, Kasparov S, Hirata AE, Campos RR, Paton JFR. Kidney-induced hypertension depends on superoxide signaling in the rostral ventrolateral medulla. Hypertension 2010; 56: 290-296.

70 Nozoe M, Hirooka Y, Koga Y, Araki S, Konno S, Kishi T, Ide T, Sunagawa K. Mitochondria-derived reactive oxygen species mediate sympathoexcitation induced by angiotensin II in the rostral ventrolateral medulla. J Hypertens 2008; 26 2176-2184.

71 Kishi T, Hirooka Y, Konno S, Ogawa K, Sunagawa K. Angiotensin II type 1 receptor activated caspase-3 through ras/mitogen-activated protein kinase/extracellular signal regulated kinase in the rostral ventrolateral medulla is involved in sympathoexcitation in stroke-prone spontaneously hypertensive rats. Hypertension 2010; 55: 291-297.

72 Chan SH, Hsu KS, Huang CC, Wang LL, Qu CC, Chan JY. NADPH oxidase-derived superoxide anion mediates angiotensin II-induced pressor effect via activation of $\mathrm{p38}$ mitogen-activated protein kinase in the rostral ventrolateral medulla. Circ Res 2005 97: 772-780.

$73 \mathrm{Hu} \mathrm{L}$, Zhu DN, Yu Z, Wang JQ, Sun ZJ, Yao T. Expression of angiotensin type 1 (AT1) receptor in the rostral ventrolateral medulla in rats. J App/ Physiol 2002; 92 2153-2161.

74 Reja V, Goodchild AK, Phillips JK, Pilowsky PM. Upregulation of angiotensin AT1 receptor and intracellular kinase gene expression in hypertensive rats. Clin Exp Pharmacol Physiol 2006; 33: 690-695.

75 Leenen $\mathrm{FHH}$. Brain mechanisms contributing to sympathetic hyperactivity and heart failure. Circ Res 2007; 101: 221-223.

76 Huang BS, Leenen FHH. The brain renin-angiotensin-aldosterone system: a major mechanism for sympathetic hyperactivity and left ventricular remodeling and dysfunction after myocardial infarction. Curr Heart Fail Rep 2009; 6: 81-88.

77 Zucker IH, Schultz HD, Patel KP, Wang W, Gao L. Regulation of central angiotensin type 1 receptors and sympathetic outflow in heart failure. Am J Physiol 2009; 297: H1557-H1566.

78 Dupont AG, Brouwers S. Brain angiotensin peptides regulate sympathetic tone and blood pressure. J Hypertens 2010; 28: 1599-1610.

79 Nozoe M, Hirooka Y, Koga Y, Sagara Y, Kishi T, Engelhardt JF, Sunagawa K. Inhibition of Rac1-derived reactive oxygen species in nucleus tractus solitarius decreases blood pressure and heart arte in stroke-prone spontaneously hypertensive rats. Hypertension 2007; 50: 62-68.

80 Zimmerman MC, Zucker IH. Mitochondrial dysfunction and mitochondria-produced reactive oxygen species: new aspects for neurogenic hypertension? Hypertension 2009; 53: 112-114.

81 Hirooka Y, Potts PD, Dampney RAL. Role of angiotensin II receptor subtypes in mediating the sympathoexcitatory effects of exogenous and endogenous angiotensin peptides in the rostral ventrolateral medulla. Brain Res 1997; 772: 107-114.

82 Dampney RAL, Tan PSP, Sheriff MJ, Fontes MAP, Horiuchi J. Cardiovascular effects of angiotensin II in the rostral ventrolateral medulla: the push-pull hypothesis. Cur Hypertens Rep 2007; 9: 222-227.

83 Shinohara K, Hirooka Y, Kishi T, Sunagawa K. Reduction of nitric oxide-mediated $\gamma$ amino butyric acid release in rostral ventrolateral medulla is involved in superoxideinduced sympathoexcitation of hypertensive rats. Circ J 2012; 76: 2814-2821.

84 Zielonka J, Zielonka M, Sikora A, Adamus J, Joseph J, Hardy M, Ouari O, Dranka BP, Kalyanaraman B. Global profiling of reactive oxygen and nitrogen species in biological systems: high-throughput real-time analysis. J Biol Chem 2012; 287: 2984-2995.

85 Zanzinger J. Mechanisms of action of nitric oxide in the brain stem: role of oxidative stress. Auton Neurosci 2002; 98: 24-27.

86 Sun J, Druhan LJ, Zweler JL. Reactive oxygen and nitrogen species regulate inducible nitric oxide synthase function shifting the balance of nitric oxide and superoxide production. Arch Biochem Biophys 2010; 494: 130-137.

87 Kung LC, Chan SH, Wu KL, Ou CC, Tai MH, Chan JY. Mitochondrial respiratory enzyme complexes in rostral ventrolateral medulla as cellular targets of nitric oxide and superoxide interaction in the antagonism of antihypertensive action of eNOS transgene. Mol Pharmacol 2008; 74: 1319-1332.

88 Rhee SG. Cell signaling, H2O2, a necessary evil for cell signaling. Science 2006, 312: $1882-1883$

89 Yu Y, Zhang ZH, Wei SG, Serrats J, Weiss RM, Felder RB. Brain perivascular macrophages and the sympathetic response to inflammation in rats after myocardial infarction. Hypertension 2010; 55: 652-659.

90 Hirooka Y. Brain perivascular macrophages and central sympathetic activation after myocardial infarction: heart and brain interaction. Hypertension 2010; 55: 610-611.

91 Cardinale JP, Sriramula S, Mariappan N, Agarwal D, Francis J. Angiotensin II-induced hypertension is modulated by nuclear factor-kB in the paraventricular nucleus. Hypertension 2011; 59: 113-121.

92 Shi P, Diez-Freire C, Jun JY, Qi Y, Katovich MJ, Li Q, Sriramula S, Francis J, Summers C, Raizada MK. Brain microglial cytokines in neurogenic hypertension. Hypertension 2010; 56: 297-303

93 Kishi T, Hirooka Y, Sunagawa K. Autoimplantation of astrocytes into cardiovascular center of brainstem causes sympathoinhibition and decreases the mortality rate in hypertensive rats. Circulation 2010; 122: A13856.

94 Kishi T, Hirooka Y, Sunagawa K. Autoimplantation of astrocytes into the cardiovascular center of brainstem causes sympathoinhibition and decreases the mortality rate in myocardial infarction-induced heart failure. Circulation 2011; 124: A11489.

95 Kumagai H, Oshima N, Matsuura T, ligaya K, Imai M, Onimaru H, Sakata K, Osaka M Onami T, Takimoto C, Kamayachi T, Itoh H, Saruta $\mathrm{T}$. Importance of rostral ventrolateral medulla neurons in determining efferent sympathetic nerve activity and blood pressure. Hypertens Res 2012; 35: 132-141.

96 Matsuura T, Kumagai H, Kawai A, Onimaru H, Imai M, Oshima N, Sakata K, Saruta T. Rostral ventrolateral medulla neurons of neonatal Wister-Kyoto and spontaneously hypertensive rats. Hypertension 2002; 40: 560-565.

97 Oshima N, Kumagai H, Onimaru H, Kawai A, Pilowski PM, ligaya K, Takimoto C Hayashi K, Saruta T, Itoh H. Monosynaptic excitatory connection from the rostral ventrolateral medulla to sympathetic pregangionic neurons revealed by simultaneous recording. Hypertens Res 2008; 31: 1445-1454

$98 \mathrm{Wu}$ KL, Chan SH, Chan JY. Neuroinflammation and oxidative stress in rostra ventrolateral medulla contribute to neurogenic hypertension induced by systemic inflammation. J Neuroinflammation 2012; 9: 212

99 Gao L, Li Y, Schultz HD, Wang WZ, Finch M, Smith LM, Zucker IH. Downregulated Kv4.3 expression in the RVLM as a potential mechanism for sympathoexcitation in rats with chronic heart failure. Am J Physiol 2010; 298: H945-H955.

100 Allen AM, MacGregor DP, McKinley MJ, Mendelsohn FAO. Angiotensin II receptors in the human brain. Regul Pept 1999; 79: 1-7.

101 McKinley MJ, Albiston AL, Allen AM, Mathai ML, May CN, McAllen RM, Oldfield BJ, Mendelsohn FAO, Chai SY. The brain renin-angiotensin system: location and physiological roles. Int J Biochem Cell Biol 2003; 35: 901-918.

102 Wang JM, Tan J, Leenen FHH. Central nervous system blockade by periphera administration of AT1 receptor blockers. J Cardiovasc Pharmacol 2003; 41: 593-599.

103 Tsuchihashi T, Kagiyama S, Matsumura K, Abe I, Fujishima M. Effects of chronic ora treatment with imidapril and TCV-116 on the responsiveness to angiotensin II in ventrolateral medulla of SHR. J Hypertens 1999; 17: 917-922.

104 Nishimura Y, Ito T, Hoe KL, Saavedra JM. Chronic peripheral administration of the angiotensin II AT1 receptor antagonist candesartan blocks brain AT1 receptors. Brain Res 2000; 871: 29-38.

105 Gohlke P, Weiss S, Jansen A, Wienen W, Stangier J, Rascher W, Culman J, Unger T. AT1 receptor antagonist telmisartan administered peripherally inhibits central responses to angiotensin II in conscious rats. J Pharmacol Exp Ther 2001; 298: 62-70.

106 Leenen FHH, Yuan B. Prevention of hypertension by irbesartan in Dahl S rats relates to central angiotensin II type 1 receptor blockade. Hypertension 2001; 37: 981-984.

107 Lin Y, Matsumura K, Kagiyama S, Fukuhara M, Fujii K, lida M. Chronic administration of olmesartan attenuates the exaggerated pressor response to glutamate in the rostral ventrolateral medulla of SHR. Brain Res 2005; 1058: 161-166.

108 Araki S, Hirooka Y, Kishi T, Yasukawa K, Utsumi H, Sunagawa K. Olmesartan reduces stress in the brain of stroke-prone spontaneously hypertensive rats assessed by an in vivo ESR method. Hypertens Res 2009; 32: 1091-1096.

109 Golomb BA, Dimsdale JE, White HL, Ritchie JB, Criqui MH. Reduction in blood pressure with statins: results from the USCD Statin Study, a randomized trial. Arch Intern Med 2008; 168: 721-727.

110 Sinski M, Lewandowsk J, Ciarka A, Bidiuk J, Abramczyk P, Dobosiewicz A, Gaciong Z. Atorvastatin reduced sympathetic activity and increases baroreceptor reflex sensitivity in patients with hypercholesterolemia and systemic arterial hypertension. Kardiol Pol 2009; 67: 613-620.

111 Kishi T, Hirooka Y. Sympathoinhibitory effects of atorvastatin in hypertension. Circ $J$ 2010; 74: 2552-2553.

112 Siddiqi L, Joles JA, Oey PL, Blankestijn PJ. Atorvastatin reduced sympathetic activity in patients with chronic kidney disease. J Hypertens 2011; 29: 2176-2180.

113 Wassmann S, Laufs U, Muller K, Konkol C, Ahlbory K, Baumer AT, Linz W, Bohm M, Nickenig G. Cellular antioxidant effects of atorvastatin in vitro and in vivo. Arterioscle Thromb Vasc Biol 2002; 22: 300-305

114 Kishi T, Hirooka Y, Mukai Y, Shimokawa H, Takeshita A. Atorvastatin causes depressor and sympathoinhibitory effects with upregulation of nitric oxide synthase in strokeprone spontaneously hypertensive rats. J Hypertens 2003; 21: 379-386.

115 Hirooka Y, Kimura Y, Nozoe M, Sagara Y, Ito K, Sunagawa K. Amlodipine-induced reduction of oxidative stress in the brain is associated with sympatho-inhibitory effects in stroke-prone spontaneously hypertensive rats. Hypertens Res 2006; 29 49-56. 
116 Shinohara K, Hirooka Y, Ogawa K, Kishi T, Yasukawa K, Utsumi H, Sunagawa K. Combination therapy of olmesartan and azelnidipine inhibits sympathetic activity associated with reducing oxidative stress in the brain of hypertensive rats. Clin Exp Hypertens 2012; 34: 456-464.

117 Iwanami J, Mogi M, Iwai M, Horiuchi M. Inhibition of the renin-angiotensin system and target organ protection. Hypertens Res 2009; 32: 229-237.

118 Mogi M, Horiuchi M. Effects of angiotensin II receptor blockers on dementia. Hypertens Res 2009; 32: 738-740.

119 Krum H, Schlaich MP, Whitbourn R, Sobotka P, Sadowski J, Bartus K, Kapelak B, Walton A, Sievert $H$, Thambar S, Abraham WT, Esler M. Catheter-based renal sympathetic denervation for resistant hypertension: a multicentre safety and proofof principle cohort study. Lancet 2009; 373: 1275-1281.

120 DiBona GF, Esler M. Translational medicine: the antihypertensive effect of renal denervation. Am J Physiol 2010; 298: R245-R253.
121 Simplicity HTN-2 Investigators. Renal sympathetic denervation in patients with treatment-resistant hypertension (The Simplicity HTN-2 Trail): a randomized controlled trial. Lancet 2010; 376: 1903-1909.

122 Calaresu FR, Ciriello J. Renal afferent nerves affect discharge rate of medullary and hypothalamic single units in cat. J Auton Nerv Syst 1981; 3: 311-320.

123 Stella A, Golin R, Genovesi S, Zanchetti A. Renal reflexes in the regulation of blood pressure and sodium excretion. Can J Physiol Pharmacol 1987; 65: 1536-1539.

124 Ye S, Zhong H, Campese VM. Oxidative stress mediates the sympathetic nerve activity in the phenol renal injury model of hypertension. Hypertension 2006; 48 : 309-315.

125 Campese VM, Shaohua Y, Huiquin Z. Oxidative stress mediates angiotensin II-dependent stimulation of sympathetic nerve activity. Hypertension 2005; 46: 533-539. 